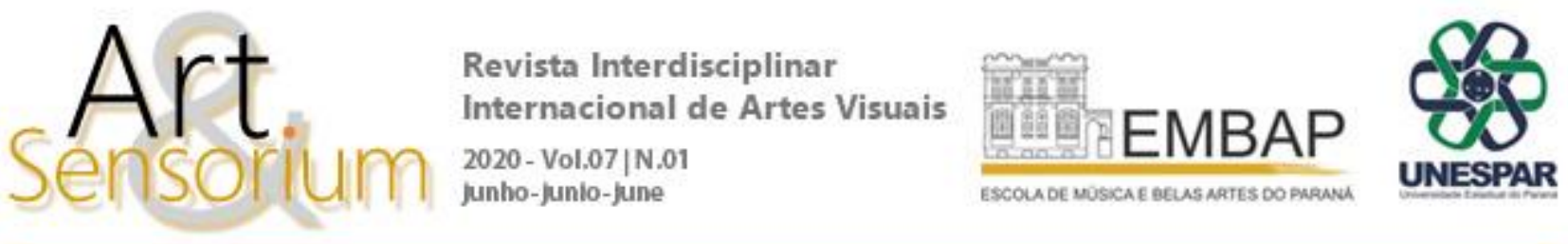

\title{
QUANDO A PERFORMANCE COMEÇA?: UMA POÉTICA EDIFICADA SOBRE A AFETIVIDADE E A CIBERCULTURA \\ DOI: https://doi.org/10.33871/23580437.2020.7.1.16-27
}

\author{
Marcella Nunes Rodrigues ${ }^{1}$ \\ Gisela Reis Biancalana ${ }^{2}$
}

RESUMO: O artigo apresenta o estudo, elaboração e execução de uma ação performativa transversal que parte de uma pesquisa em Poéticas Visuais na Arte Contemporânea. O objetivo do estudo se constituiu da criação de uma Performance que discutiu a entrada da tecnologia nos relacionamentos afetivos. A Performance Arte tem atraído inúmeros artistas pela potência do corpo em estado de arte. Por outro lado, nos últimos tempos, a convivência com ambientes virtuais tornou-se uma constante na vida humana. Aqui, a Performance buscou abranger arte, corpo e comunicação. As teóricas Goldberg e Taylor sustentaram e fortaleceram as ações performativas nos seus aspectos teóricopráticos, sobretudo no que tange à imersão nessas questões sociais latentes e manifestas. No que diz respeito aos relacionamentos afetivos e suas transformações no mundo contemporâneo, Bauman sedimentou a pesquisa com sua abordagem do mundo líquido aqui vislumbrado nas relações afetivas cruzadas pelos contatos no mundo virtual. Nesse contexto, as relações afetivas foram estudadas a partir de suas novas possibilidades de configuração calcadas no uso de dispositivos tecnológicos que constroem o que Santaella chama de cibercultura. Os procedimentos metodológicos buscaram dialogar com a antropologia no que diz respeito à pesquisa de campo, subsidiada por um viés autoetnográfico discutido a partir das autoras Fortin e Versiani. Finalmente, o texto aborda a ação Quando começa uma Performance? cujos processos criadores são expostos ao longo desta escrita reflexiva.

Palavras-chave: Performance Arte; Relações afetivas; Cibercultura; Autoetnografia.

\footnotetext{
${ }^{1}$ Marcella Nunes Rodrigues. Doutoranda no Programa de Pós-Graduação em Artes Visuais, Universidade Federal de Santa Maria (UFSM) e mestre em Artes Visuais pelo mesmo Programa. Graduada em Dança Bacharelado pela UFSM. Participante do grupo de pesquisas Performances: arte e cultura, vinculado ao CNPQ, no qual investiga relações entre arte e universos socioculturais em processos de criação. Desenvolve pesquisas relacionadas à Performance Arte.

${ }^{2}$ Gisela Reis Biancalana. Professora do Centro de Artes e Letras e membro permanente do Programa de Pós Graduação em Artes Visuais (PPGART), ambos na UFSM. Mestre e Doutora em Artes pela UNICAMP. É líder do grupo de pesquisas Performances: arte e cultura, vinculado ao CNPQ, no qual investiga relações entre arte e universos socioculturais na criação de Performances Arte. Entre os anos de 2014-2015 realizou pós-doutoramento na De Montfort University, Leicester, UK, investigando processos colaborativos de criação. Entre as publicações de livros, capítulos e artigos destaca-se a organização dos volumes I e II de Discursos do Corpo na Arte.
} 


\title{
WHEN DOES THE PERFORMANCE BEGIN?: A POETICS BUILT ON AFFECTIVITY AND CYBERCULTURE
}

\begin{abstract}
The article presents the study, elaboration and execution of a transversal performative action that starts from a research in Visual Poetics in Contemporary Art. The purpose of the study was to create a Performance that discusses the entry of technology in affective relationships. Performance Arte has attracted countless artists due to the power of the body in a state of art. On the other hand, in recent times, living with virtual environments has become a constant in human life. Here, Performace seeks to cover art, body and communication. Theorists Goldberg and Taylor supported and strengthened the performative actions in their theoretical-practical aspects, especially with regard to immersion in these latent and manifest social issues. With regard to affective relationships and their transformations in the contemporary world, Bauman consolidated this research with his approach to the liquid world here glimpsed in the affective relationships crossed by contacts in the virtual world. In this context, affective relationships were studied based on their new possibilities of configuration based on the use of technological devices that build what Santaella calls cyberculture. The methodological procedures sought to dialogue with anthropology in terms of field research, supported by an autoethnographic bias discussed by the authors Fortin and Versiani. Finally, the text addresses the action When does a Performance begin? whose creative processes are exposed throughout this reflective writing.
\end{abstract}

Keywords: Performance Art; Affective relationships; Cyberculture; Autoethnography.

\section{CUÁNDO EMPEZA LA ACTUACIÓN?: UNA POÉTICA CONSTRUIDA SOBRE LA AFECTIVIDAD Y LA CIBERCULTURA}

RESUMEN: El artículo presenta el estudio, elaboración y ejecución de una acción performativa transversal que parte de una investigación en Poética visual en el arte contemporáneo. El propósito del estudio fue crear un rendimiento que discute la entrada de la tecnología en las relaciones afectivas. Performance Arte ha atraído a innumerables artistas debido al poder del cuerpo en un estado de la técnica. Por otro lado, en los últimos tiempos, vivir con entornos virtuales se ha convertido en una constante en la vida humana. Aquí, Performace busca cubrir el arte, el cuerpo y la comunicación. Los teóricos Goldberg y Taylor apoyaron y fortalecieron las acciones performativas en sus aspectos teórico-prácticos, especialmente con respecto a la inmersión en estos problemas sociales latentes y manifiestos. Con respecto a las relaciones afectivas y sus transformaciones en el mundo contemporáneo, Bauman consolidó la investigación con su enfoque del mundo líquido aquí vislumbrado en las relaciones afectivas cruzadas por los contactos en el mundo virtual. En este contexto, se estudiaron las relaciones afectivas en función de sus nuevas posibilidades de configuración basada en el uso de dispositivos tecnológicos que construyen lo que Santaella llama cibercultura. Los procedimientos metodológicos buscaron dialogar con la antropología con respecto a la investigación de campo, con el apoyo de un sesgo autoetnográfico discutido por los autores Fortin y Versiani. Finalmente, el texto aborda el acción Cuándo empeza una Performance? cuyos procesos creativos están expuestos a lo largo de esta escritura reflexiva.

Palabras clave: Performance Art; Relaciones afectivas; Cibercultura; Autoetnografía. 
A Performance é uma manifestação artística que possibilita ao seu agente, um vasto campo de criação a partir da ativação corpo posto em estado de arte. Não são poucos os autores que remetem à amplitude e complexidade da Performance não apenas em seus campos de estudo teórico, histórico e sociocultural. Há, ainda, sua abordagem enquanto ação prática inserida no contexto da criação, ou seja, enquanto manifestação artística a qual nos referimos nesta pesquisa de caráter transversal.

Antes de tudo, vale apontar o caráter transversal deste estudo. Os cruzamentos entre campos de conhecimento têm sido cada vez mais frequentes nas pesquisas acadêmicas por todo mundo. Parte desse fenômeno acontece devido à percepção e conscientização crescentes de que os saberes e fazeres não existem isolados de atravessamentos diversos. Não se trata de negar as especializações, mas de atentar, também, para uma dimensão que retoma a importância desses cruzamentos. Neste contexto, palavras como inter e transdisciplinaridade, transversalidade, entre outras passam a compor muitos ambientes investigativos. Além dos atravessamentos entre campos de saberes distantes, também são frequentes interpenetramentos no interior de um mesmo campo, como as artes, por exemplo, que se expandem vertiginosamente. Assim, a transversalidade nas artes tem gerado férteis caldos de produção artística desde meados do século XX quando o modernismo passa, entre outros gritos provocadores, a questionar as fronteiras eurocêntricas historicamente impostas pelos colonizadores. Não se trata de negar a autonomia dos saberes que nos contaminaram, tampouco negar o valor desses fazeres que constituem uma significativa contribuição para o mundo. Trata-se apenas de situar e lembrar que a valorização de uns saberes-fazeres sobre outros também se engendra pelas relações de poderes estabelecidos. Este estudo está atravessado por campos diversos, mas principalmente situase nos cruzamentos entre as artes visuais, o corpo cênico e a antropologia.

Assim, neste artigo apresentamos alguns dos fundamentos de uma pesquisa transversal voltada para o intercâmbio, sobretudo entre o corpo performativo e elementos oriundos da antropologia como campo de conhecimento. Este último remete à cultura, especificamente à cibercultura e à adoção da pesquisa de campo e da autoetnografia como procedimento metodológico da prática. Este percurso vai constituir o material que tem sido base da poética desenvolvida nesta pesquisa. Porém, este texto se debruça, especificamente sobre uma das performances de uma série, intitulada Quando a performance começa?.

A abordagem transversal é conclamada aqui à medida que se pensa para além do conceito de disciplina presente na inter e na transdisciplinariedade, mas ao mesmo tempo, necessariamente passa por eles. Este estudo apela para as disciplinas instituídas e presentes nesta pesquisa não no sentido de agrupa-las, trança-las ou mesmo apenas transcendê-las na criação de um novo saber. A tentativa aqui é edificar um modus operandi que considere o próprio artista-pesquisador, bem como o movimento incessante do mundo contemporâneo no percurso da investigação.

Os autores nos quais baseamos nossas questões de pesquisa foram escolhidos de campos de conhecimento diversos a fim de coloca-los em diálogo transdisciplinar com uma intencional promiscuidade teórica que procura andar ao lado de bases epistemológicas e metodológicas consistentes. Entre esses autores destacamos, sobretudo, Goldberg, Taylor, Bauman, Hall, Santaella, Fortin e Versiani. Desse modo, entendemos a transdisciplinariedade, aqui, renunciando à visão piramidal do conhecimento. O pensamento clássico considera que cada fragmento da pirâmide, gerado pelo bigbang disciplinar, poderia ser uma pirâmide inteira, pois cada disciplina proclama que o campo de sua pertinência é inesgotável. Para o pensamento clássico, a transdisciplinaridade talvez fosse um absurdo. Para as proposições transdisciplinares, por sua vez, o pensamento clássico não é absurdo, mas seu campo de aplicação é restrito. Enfim, para tal, a edificação desta reflexão escrita sobre o trabalho Quando uma performance começa?, pretendeu realizar um percurso que inicia com a organização do espaço pensando na visualidade e nas materialidades da ação performativa, passa pela experiência do corpo no ambiente e finaliza com a sua presença na própria rede social, a qual é justamente sobre o que a proposta fala recebendo interferências dos sujeitos inseridos naquela rede social. 
$\mathrm{Na}$ esteira desse pensamento, este trabalho desenvolvido em poéticas da criação encontrou-se acolhido pela Arte da Performance, justamente por dissolver fronteiras atuando no campo expandido da arte contemporânea. É aqui que o corpo se manifesta como centro de irradiação de seus saberesfazeres. Sendo assim, da mesma forma que os modos de ser/estar/pensar/fazer/sentir contemporâneos têm se modificado - e, em parte, se virtualizado progressivamente, a arte também tem ganhado outras espacialidades, dinâmicas, modos de se relacionar entre si e com o público. Nesse contexto expandido, essa manifestação artística surge como um redutor de alienação em vários aspectos estéticos e políticos. Goldberg (2006) ressalta um desses aspectos estéticos quando repensa as relações entre o público e o artista ressaltando que ambos podem vivenciar a obra simultaneamente.

A Foto-Performance intitulada Quando a performance começa? está calcada na ideia presente de felicidade instantânea recortada nas fotos das redes sociais. Hall (1997, p. 4) expõe as mudanças sociais que têm ocorrido no mundo contemporâneo como deslocamento cultural que tem aparecido também no modo de se relacionar das pessoas. Tal fato ainda acontece, talvez, pela instantaneidade com que as conexões são feitas e desfeitas. É impressionante o ritmo acelerado das mudanças tecnológicas e os consequentes impactos culturais que elas provocam no mundo (SANTAELLA, 2003, p. 65). As realidades de espaço e tempo tem se alterado nas postagens pelas redes sociais. Segundo Hall (1997, p. 5), a cultura está fortemente presente nas imagens expostas nas telas que são compartilhadas quase que em tempo integral nos últimos anos. As relações dos casais, a maternidade, as viagens, as comidas, as casas, tudo parece mais lindo na vida de um conhecido, seja nas relações de parentesco, um amigo ou amiga virtual. Bauman (2011) coloca essa multiplicidade de imagens compartilhadas como possíveis obstáculos e desafios, já que são novas maneiras das pessoas se relacionarem entre si e com o mundo. Como já dizia uma antiga frase popular: "a grama do vizinho sempre parece mais verde!".

Esta pesquisa está ancorada no procedimento metodológico autoetnográfico, pois os novos modos de relacionamento vislumbrados pelo quanto o mundo conectado liga as pessoas reverbera-se nos próprios pesquisadores. As diversas sensações provocadas e observadas coexistem e são recorrentes nas próprias experiências dos pesquisadores conectadas às experiências do outro. Este trabalho não assume o rigor investigativo de uma pesquisa inserida nas ciências sociais e humanas por não ser, de fato, uma pesquisa antropológica. Sua intenção reside apenas no diálogo que toma de empréstimo sua perspectiva metodológica para, depois aplica-la às questões da pesquisa ancoradas na arte contemporânea. Portanto, compreendemos que a sensibilidade não nos abandona mesmo enquanto pesquisadoras, isso não estanca o estado de artista, pelo contrário, o enfatiza. Acreditamos que o instrumento autoetnográfico pode impulsionar artistas criadores a vivenciar suas pesquisas na própria carne como escolha processual do percurso.

Fortin entende que "a autoetnografia se caracteriza por uma escrita do 'eu' que permite o ir e vir entre as experiências pessoais e as dimensões culturais (...)" (2009, p. 83). Ou seja, o olhar do autor tem tanto valor quanto os fatos, sendo valorizado o seu próprio modo de ver e sentir. As vivências misturam-se e não há mais como distinguir, no processo, artistas e indivíduos pesquisados. Para Versiani (2002, p. 67), "a não negação da experiência pessoal e, principalmente, a explicitação da intersubjetividade estabelecida entre etnógrafo e etnografado como pressuposto básico da construção da própria etnografia", formatam uma relação que transborda na pesquisa. Esta relação pode potencializar o processo de criação possibilitando, no caso do artista visual, um transbordamento do autor na obra. Porém, a partir desta compreensão inicial situamos aqui à necessidade de uma atenção redobrada, pois a pesquisa autoetnográfica não deve se limitar somente ao olhar e experiência do autor.

A ação desta Performance, foi a de deixar o quarto da performer bagunçado por vários dias, acumulando roupas, livros, todos os acessórios usados no dia a dia, restos de comida ingerida ali, além de toda desordem que a permanência constante naquele lugar poderia imprimir. Após sete dias, a Foto-Performance foi realizada. No meio de toda aquela bagunça, um pequeno espaço foi aberto e arrumado para realizar uma selfie. Uma caneca foi organizada e posicionada de forma premeditada 
com o escrito "Faça o que te faz feliz!". Esta frase ganhou alguns likes, ação que determina o quanto as pessoas curtiram o que se postou na internet.

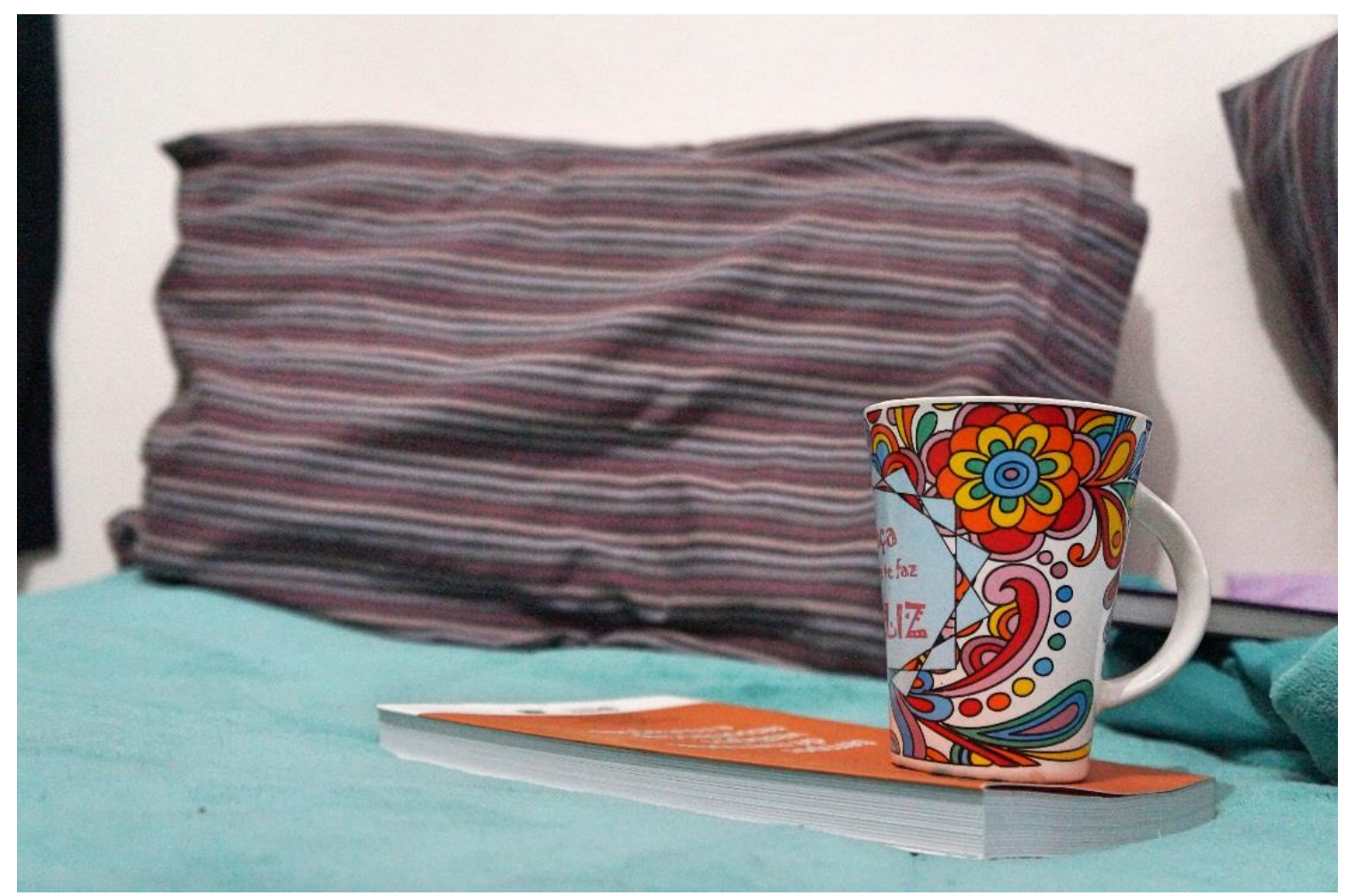

Figura 1: Foto-Performance Quando a performance começa? (2019)

Fonte: Bruna Regina Carvalho (2019).

Assim, com o espaço organizado, as roupas de ficar em casa são vestidas, o cabelo fica emaranhado e o momento da selfie se aproxima. A arrumação foi somente do tronco do corpo para cima com uma maquiagem singela para demonstrar o quanto a performer estava feliz em casa. Depois de tudo pronto, a selfie foi feita. A performer posicionou-se de modo que expressasse felicidade mostrando para a tela aquela caneca feliz com cuidado para que não aparecesse a bagunça pela volta e, também, para que a câmera registrasse somente o que se queria mostrar: o belo, o organizado, a harmonia, a paz vivida naquele momento no lar. 


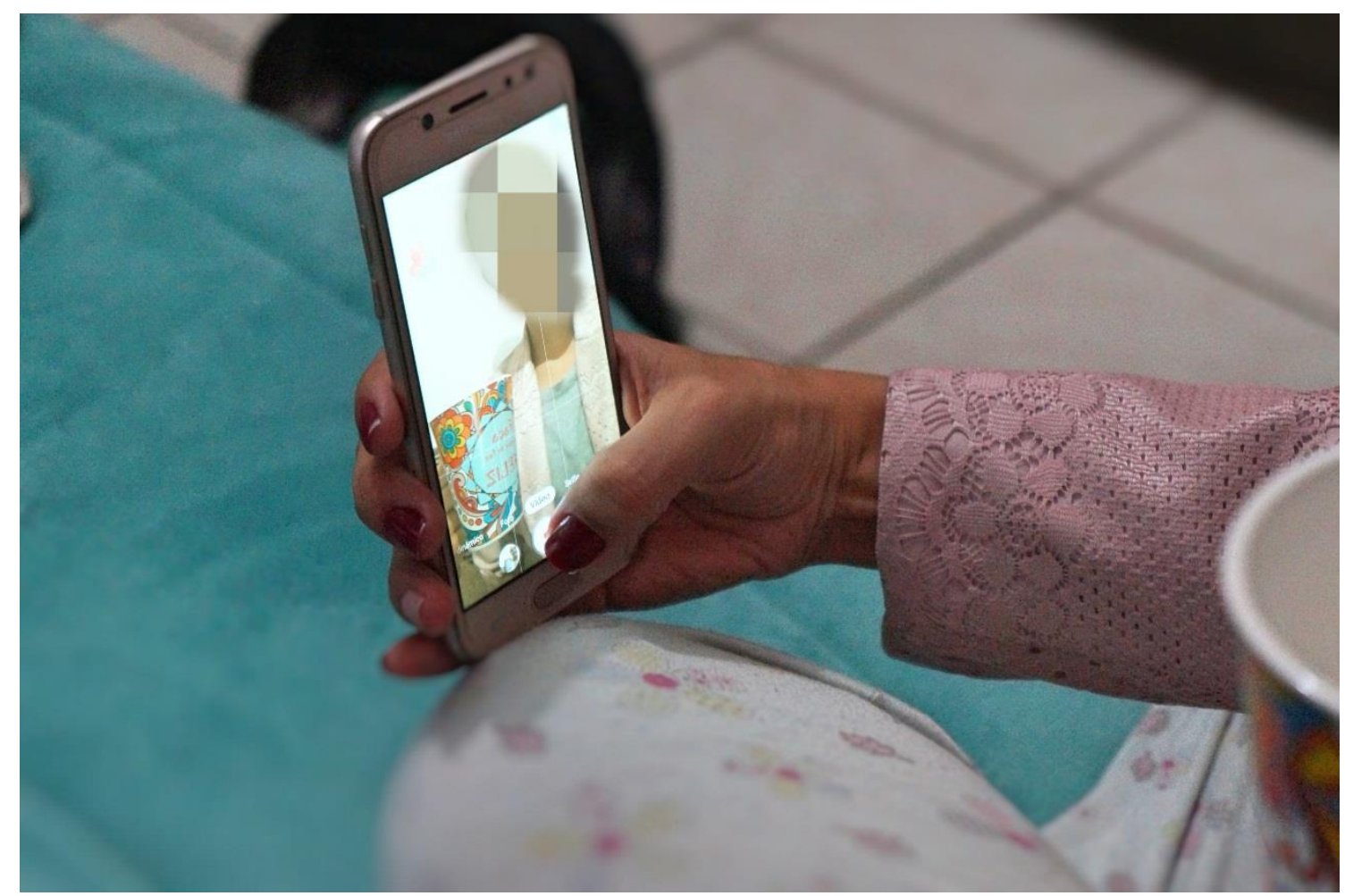

Figura 2: Foto-Performance Quando a performance começa? (2019)

Fonte: Bruna Regina Carvalho (2019).

A imagem a ser compartilhada foi propositalmente editada com uma espécie de roteiro no tempo. A selfie não demonstrou qualquer fraqueza ou desorganização, afinal, não é assim que se gera admiradores na internet. Por traz disso, o que na verdade estava explícito era o caos instaurado no quarto como resultado da realidade oriunda da falta de tempo, correria do dia a dia, falta de vontade de arrumá-lo, dentre muitas possibilidades que expressam e comunicam o estado de desorganização do espaço no cotidiano. Existem diferenças entre a vida real e a vida virtual? Por que aparentemente não há espaço na vida virtual para a bagunça? Para o caos? Em que momento a vida social virtual tornou-se um espaço predominantemente para o bem-sucedido? Para a felicidade? Estas foram algumas das questões que motivaram a criação desta Foto-Performance. A última foto da sequência de registros revela como o espaço real estava. Quando é ampliado o foco da câmera é possível vê-lo inteiramente, a concretude crua da realidade diferente daquela que aparenta um recorte de felicidade arranjado. 


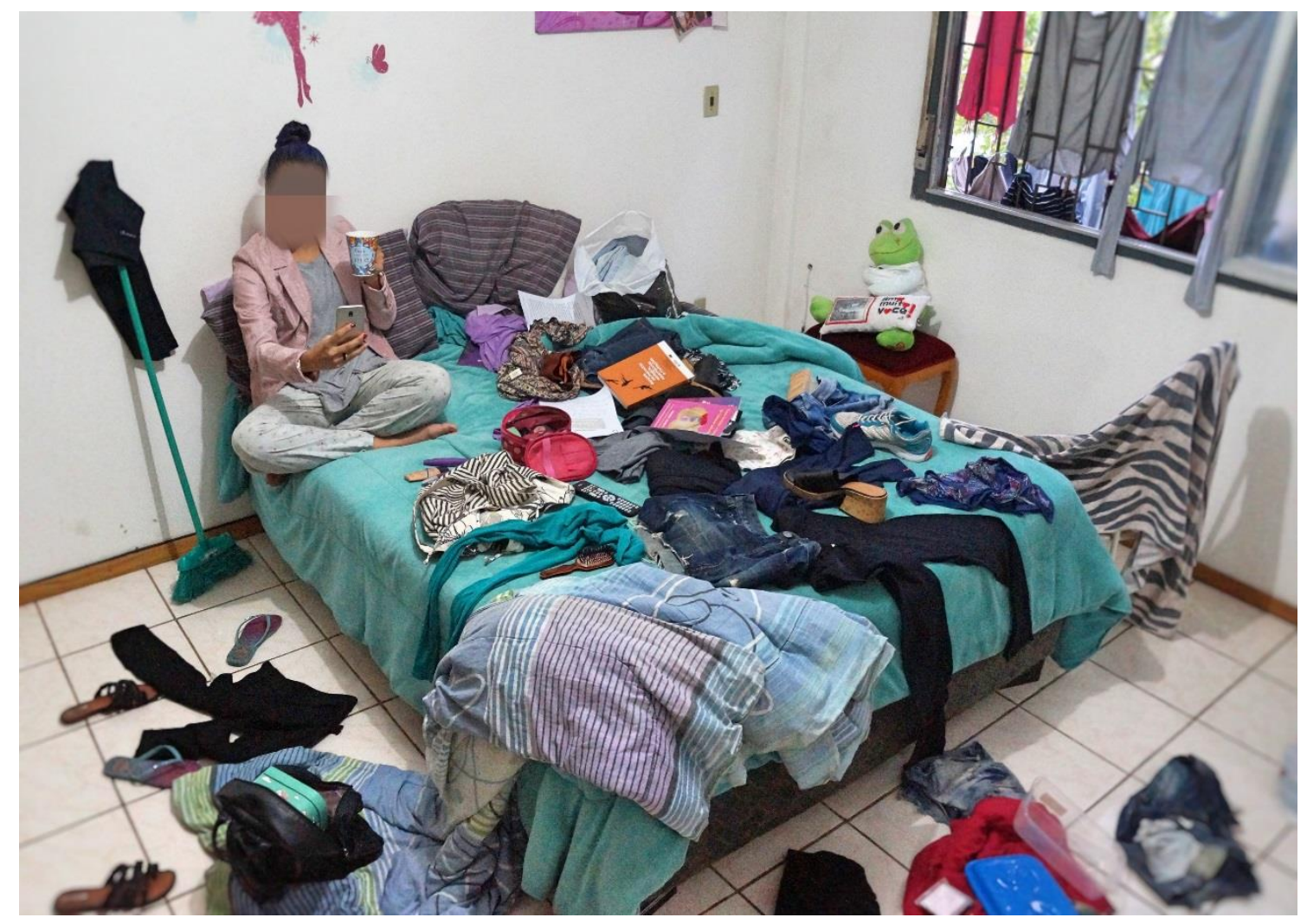

Figura 3: Foto-Performance Quando a performance começa? (2019)

Fonte: Bruna Regina Carvalho (2019).

A opção foi realizar essa Foto-Performance nas redes sociais já que a poética, como um todo, apresenta assuntos referentes à inserção de pessoas no mundo online bem como seus novos modos de se relacionar, em especial, as relações afetivas. É significativo notar que, justamente nos dias de hoje, com a ameaça latente do novo corona vírus e o rastro de situações ambíguas que ele tem causado destruição e aproximação - esse tipo de relação tornou-se ainda mais frequente. Além disso, as relações virtuais assumem certa responsabilidade a mediada que são, também, um recurso que permite, ao menos, a não instauração, em alguns casos, da completa solidão.

Basmaun (1995, p. 8) afirma que existe uma mobilização de novos fazeres artísticos que tem ampliado espaços-tempos, com a possibilidade de expandir o acesso às obras de arte, quando elas estão inseridas também nas redes. Este trabalho não trata apenas de expandir o acesso, mas de discutir alguns modos de manipulação que esta expansão tem representado e que acontecem para além do mundo da arte. As esferas políticas aproveitam-se deveras deste recurso. Esta foi a primeira Performance desta poética que foi realizada fora de um ambiente presencial, ou melhor, que experimentou sair do real e passear pelo virtual artisticamente. Taylor (2011, p. 20) cita que a Performance está excluída de qualquer tipo de enrijecimento, portanto, essas práticas não estáveis, ultrapassam territórios pré-estabelecidos. Bauman $(2011$, p. 19) ressalta essa questão quando diz que as redes têm substituído as estruturas.

No dia 13 de novembro de 2019, por volta das 20 horas e 55 minutos, a Foto-Performance foi postada nos perfis da artista, tanto no Facebook quanto no Instagram. A seguinte legenda questionava o leitor sobre sua opinião em relação à imagem que estava ali na timeline: "Nas redes sociais existem espaço para o que é dito feio? Triste? Há espaço para a bagunça, para a desorganização, seja física ou emocional? A vida virtual é uma? E a real é outra?" 


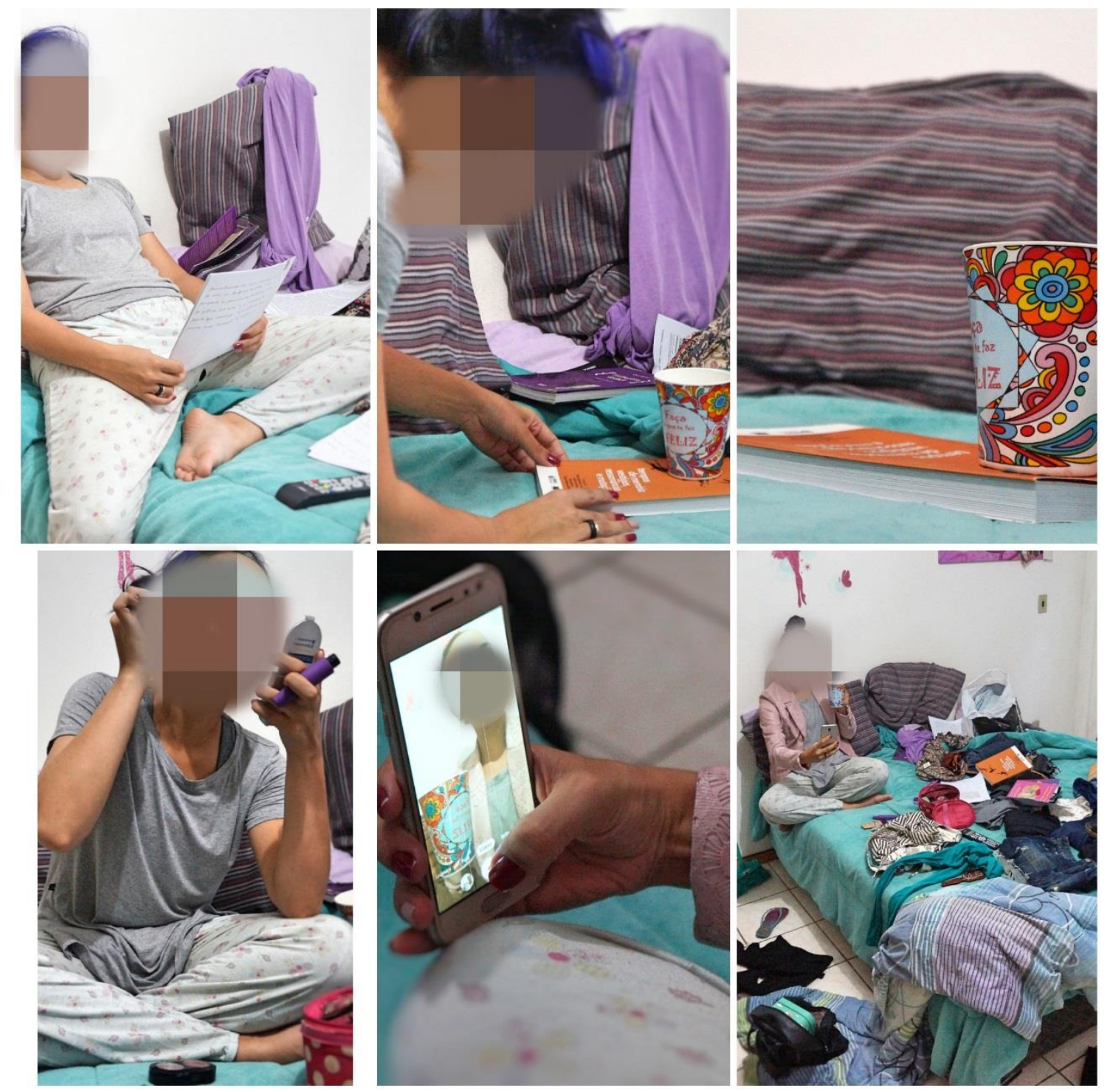

Figura 4: Foto-Performance Quando a performance começa? (2019)

Fonte: Bruna Regina Carvalho (2019).

Um grande número de pessoas conhecidas virtuais, em questão de instantes, compartilhou suas opiniões interagindo com a obra. É interessante observar que somente mulheres comentaram nas redes sociais a Foto-Performance. A manifestação do público feminino em relação à obra aconteceu de forma bastante rápida, alcançando mulheres que há tempos a artista não via. Os comentários abaixo da imagem demonstram o quão duplas se dão estas vidas, ditas reais, ditas virtuais. Existem fronteiras entre estes modos de viver? Existem limites ou regras estipuladas? Estamos vivendo um momento no qual os dispositivos tecnológicos já estão disponíveis a um grande número de pessoas, mas ainda estamos aprendendo a lidar com eles em várias dimensões da ação humana, da política à jurídica. 


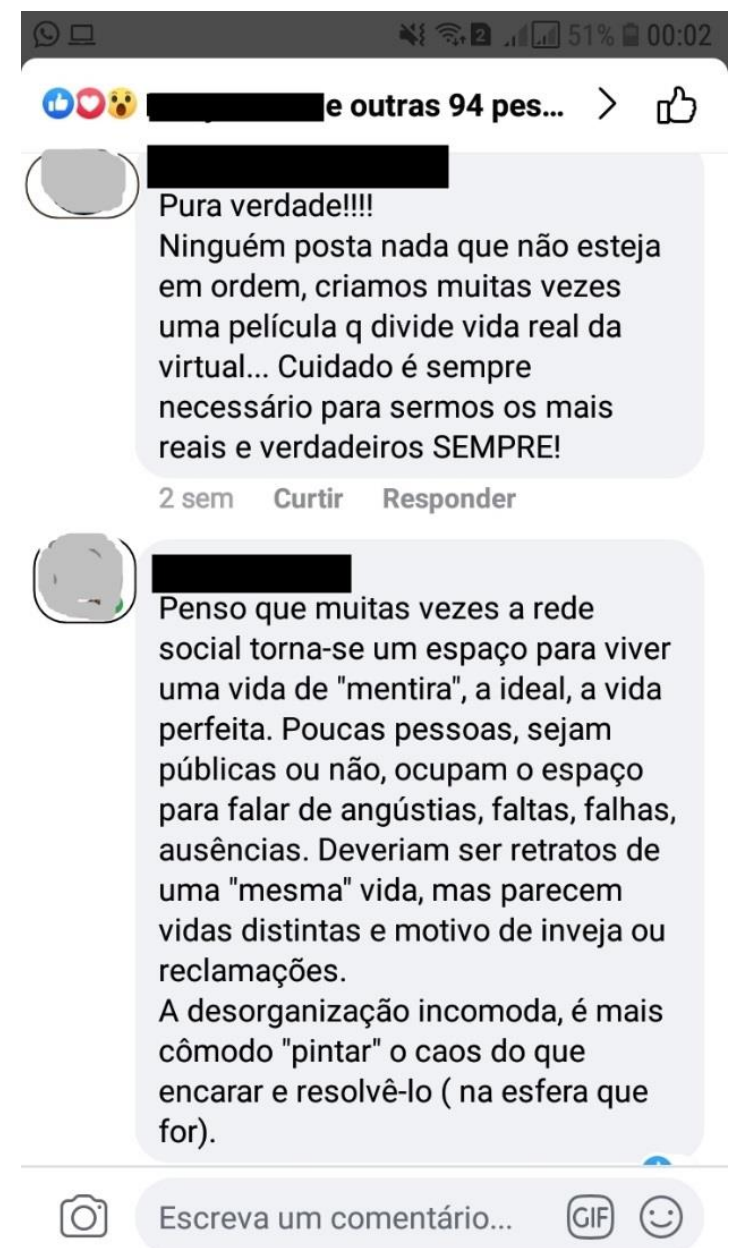

Figura 5: Print de comentários da Foto-Performance Quando a performance começa? no Facebook (2019) Fonte: a autora (2019).

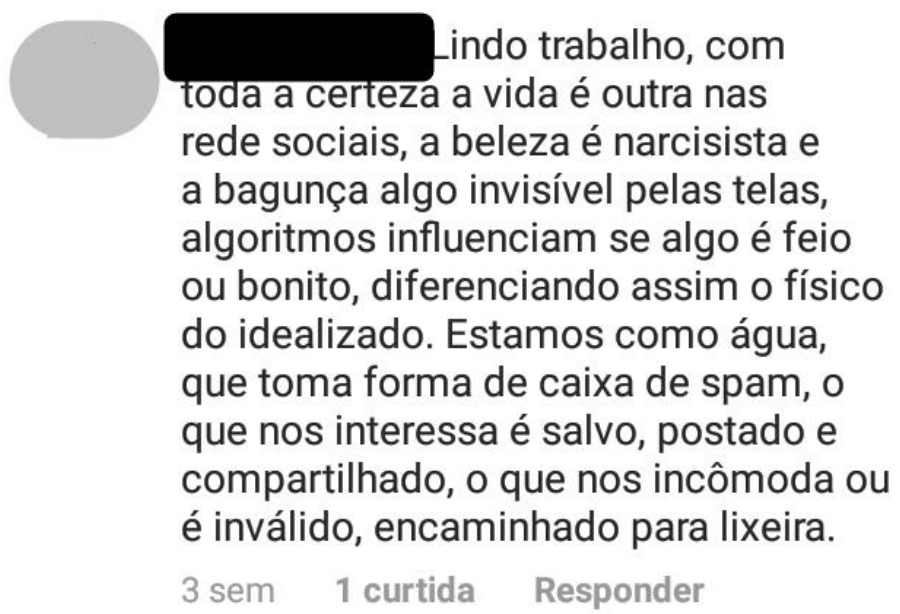

Figura 6: Print de comentários da Foto-Performance Quando a performance começa? no Instagram (2019) Fonte: a autora (2019). 
Iniciamos então algumas reflexões sobre esse público feminino ao qual nos remetemos acima. As reflexões recaem sobre as mulheres manifestas desta época na pesquisa relacionado-as aos discursos das pensadoras da Segunda Onda Feminista. Seus discursos equalizam as questões de sexualidade, violência, família, mercado de trabalho e direitos reprodutivos. As relações estabelecidas por nós tematizam os atravessamentos das mulheres na Performance Quando uma performance começa? Seus discursos ainda constituem um julgamento crítico sobre o abuso sistêmico envolvido nas soluções ortodoxas de projeto de vida feminino. Simone de Beauvoir (1949) e suas reflexões sobre a consolidação das estruturas de opressão feminina, e Betty Friedan (1971) que avalia as relações entre as mulheres e o capitalismo de consumo, nos levam a considerar a reestruturação das relações afetivas e de poder no território doméstico brasileiro.

A psicóloga Betty Friedan (1971) comenta sobre o fenômeno social do aparecimento da ansiedade em mulheres da classe média urbanizada no Estados Unidos, um sintoma dos tempos. O discurso de saberes especializados garantia que a anjo-do-lar-em-nós era o território existencial de realização da feminilidade por excelência acolhendo integralmente as intensidades e questões que pudessem atravessar a mulher. A necessidade de gestão da vida privada exigia a operação dos saberes de alavancagem da vida afetiva e familiar. Assim, a conquista e manutenção da companhia do homem, os cuidados com as necessidades dos corpos dos filhos, a capacidade de mediação de conflitos entre as diferentes gerações, o trabalho culinário, a performance cultural feminina com toda a sorte de etiquetas e vestuários adequados para a aceitação e reconhecimento social seriam capazes de garantir a realização pessoal e subjetiva das mulheres.

O consenso sobre aquelas que buscavam uma realização em carreiras profissionais seja como artistas, políticas ou médicas, entre outras, era de que se tratavam de seres adoecidos, neuróticos, estranhos ou mesmo que lhes faltava alguma coisa. "Em fins da década de cinquenta, a média etária relativa ao casamento baixou para vinte anos entre as mulheres americanas e continuava a cair, descendo à adolescência. Havia quatorze milhões de moças noivas aos 17 anos.” (FRIEDAN, 1971, p. 18) A supervalorização dos relacionamentos heteroafetivos na produção de sentido para mulheres provocava um efeito cascata em que cada vez mais cedo as meninas eram convocadas a deixar a infância de lado e garantir os meios para o final feliz esperado.

$\mathrm{Na}$ ocasião do surgimento de qualquer angústia na subjetividade de uma mulher casada, apenas se acreditava que havia algum problema com ela ou com o casamento, fato este que deveria ser escondido e não comentado com outras mulheres, seja pela vergonha, incompreensão, seja porque se tratavam de potenciais rivais na luta pela apreciação masculina e social. Nos consultórios de psicanalistas, no entanto, elas de multiplicavam, gerando profunda confusão entre os especialistas que não entendiam porque mulheres com a vida organizada dentro dos moldes hegemônicos, sem problemas sexuais, adoeciam mentalmente às centenas. É ao reconhecimento deste sofrimento inerente aos processos de condicionamento feminino que Friedan chamou o "problema sem nome".

Assim, ao refletir sobre as separações de nossos próprios pais enquanto pesquisadoras, e a separação conjugal de uma das autoras do trabalho, observamos que os questionamentos acerca dos relacionamentos afetivos ainda imperam de uma maneira ampla em meio ao público feminino, mas agora transbordam para as redes sociais. A instabilidade do próprio atravessamento do tempo desencadeia fluxos de outras memórias ainda presentes e que se deslizam para formar novos territórios no que diz respeito aos relacionamentos. O novo revela-se pela dinâmica dos contextos socioculturais reatualizados nas redes. Não é possível separar os momentos nos quais são retomadas as questões do passado e os momentos onde se abre espaço para que mulheres compartilhem suas indagações e angústias, mas sabemos que elas ainda existem.

A imagem perfeita da mulher, agora nos ambientes virtuais, ainda é requisitada. A interação do público internáutico, proporcionou-nos a percepção de que há uma necessidade urgente de se falar sobre esse período no qual estamos imersos, porém pouco conhecemos. As indagações quanto às relações e comportamentos via internet são muitas. A ferramenta está disponível, mas ética para sua 
utilização ainda demanda muitos cuidados e leis que resguardem a vida humana nos ambientes virtuais. Não se trata de encontrar um número rígido e definitivo de regras, até porque a liquidez do mundo e a transformação dos dispositivos é incessante. Trata-se, apenas, de entender esta realidade desafiadora que se apresenta e que já estamos vivendo a algumas décadas.

Sendo assim, torna-se fundamental lançar um olhar atento à importância da internet nesse processo, pois ele evidenciou a força, a rapidez e o impacto com que as redes sociais potencializam e compartilham uma imagem, em especial, uma imagem-corpo, uma imagem-mulher. Melim (2008) evidencia que procedimentos envolvendo a tecnologia multiplicam as possibilidades de alargamento e expansão das práticas artísticas. Observamos, nos retornos após a postagem da Foto-Performance, que o trabalho se difundiu ainda mais através da internet. Pela difusão das fotos nas redes, estabeleceram-se outras relações com a obra, como por exemplo, o acesso à própria pesquisa de pessoas que não frequentam a academia. Assim é possível dizer ainda, que o próprio campo da pesquisa foi ampliado. Goldberg (2006), coloca que em algum momento na Performance, houve a necessidade de aliar o uso das novas mídias à própria Performance. Aqui ela deixa de ser apenas a arte do corpo presente para alargar possibilidades que adentram nas Foto-performances, nas videoperformances, nas performances online, enfim, multiplicam-se possibilidades potentes de seu alcance como fenômeno da ação nas artes visuais. Estabeleceu-se, então, através de Quando $a$ performance começa?, uma rede com um público virtual que agora acompanha as outras Performances que compõe a poética, bem como as discussões teóricas delas decorrentes.

A Performance Quando uma performance começa? tornou o público virtual presente, compartilhando suas experiências e pensamentos acerca da proposta. O trabalho resultou em conectividade entre a artista e o público, entre a ação performativa e o público, entre a pesquisa e o público. A internet foi um dos fatores mais significativos neste trabalho, pois tornou-se agente propagador da pesquisa para fora da academia. É instigante pensar que um dos fatores mais discutidos nesta investigação, são as redes sociais e elas foram o elemento crucial na ampliação do campo da pesquisa e compartilhamento da mesma.

\section{REFERÊNCIAS}

BASMAUN, Ricardo. “E agora?”. Colaboração. s/v, p. 84-93, 1995.

BAUMAN, Zygmunt. A cultura no mundo líquido moderno. Rio de Janeiro: Jorge Zahar, 2011.

FORTIN, Sylvie. Contribuições possíveis da Etnografia e da auto-etnografia para a pesquisa na prática artística. Revista Cena, n. 7, 2009.

FRIEDAN, Betty. A mística feminina. Petrópolis: Editora Vozes, 1971.

GOLDBERG. RoseLee. A arte da performance: do futurismo ao presente. São Paulo: Martins Fontes, 2006.

HALL, Stuart. A centralidade da cultura: notas sobre as revoluções de nosso tempo. Educação \& Realidade, v. 22, n. 2, p. 15-46, 1997.

MELIM, Regina. Performance nas Artes Visuais. Rio de Janeiro: Editora Jorge Zahar, 2008. 
NICOLESCU, Basarab. UM NOVO TIPO DE CONHECIMENTO

TRANSDISICPLINARIDADE. Anais do 1o Encontro Catalisador do CETRANS - Escola do Futuro - USP. Itatiba, São Paulo - Brasil: abril de 1999.

SANTAELLA, Lucia. Culturas e Artes do Pós Humano: da cultura das mídias à cibercultura. São Paulo: Paulus, 2003.

TAYLOR, Diana. Introducción Performance, teoria y práctica. In: TAYLOR, Diana; FUENTES, Marcela (Edits.). Estudios avanzados de performance. México: Fondo de Cultura Económica, 2011.

VERSIANI, Daniela Beccaccia. Autoetnografia: uma alternativa conceitual. Porto Alegre: Letras, 2002. 